\title{
Augmented Reality 3D Cubes Puzzle Bingo Game for the Elderly
}

\author{
Woan Ning Lim, Yunli Lee, Ivan Anggoro \\ Department of Computing and Information Systems \\ School of Science and Technology \\ Sunway University \\ Bandar Sunway, Malaysia. \\ ( woanningl@sunway.edu.my, yunlil@sunway.edu.my )
}

\begin{abstract}
The pace of population aging is increasing dramatically over years. Living longer as well as living well is the goal of many people. Studies showed that mobile gaming can enhance the cognitive abilities and psychomotor skills of the elderly at the same time give the elderly sense of enjoyment and reduce the feeling of loneliness. Augmented reality technologies have been used to enhance traditional games and the results are positive. An Augmented Reality 3D cubes Puzzle Bingo game (ARPinGo) targeted the elderly was developed in this project by adapting the idea of rubik cubes and the puzzle and bingo board game features. The aim of this project is to gauge the response of the elderly towards the game and their acceptance of augmented reality technologies in mobile gaming. A total of 24 elderly members from D'Happy club in Petaling Jaya, Malaysia had participated in this study. A quantitative approach based on the Technology Acceptance Model (TAM) is used in the survey. The outcome of this study would provide valuable input for future development of gaming application for the elderly.
\end{abstract}

Keywords — augmented reality; mobile game; elderly

\section{INTRODUCTION}

The advances in medical and assistive technologies have prolonged the age of human beings. The aging population is increasing, by 2030 the global population of those aged above 60 years is projected to grow by $56 \%$ and double in size by 2050 [1]. We are seeing attendant challenges such as loneliness, social isolation and increased depression rates among the elderly as the elderly population rise. Several reasons of this are a lost sense of purpose in life, a lack of confidence in dealing with physical or mentally decline, and the refusal to be a burden to others [2]. Almost one third of the elderly have reported experiencing loneliness, and the loneliness is also linked to higher risks of dementia [3].

Many believe that to live longer is not the ultimate goal if without living well. Research had shown that in order to age in an active and healthy way, we need to continue learning and work out to be both physically and mentally healthy. Many initiatives and researches had been done by involving innovative uses of technologies to help the elderly. Augmented reality technologies usage is on the rise, the experience is getting better and more realistic and allow users to add virtual layers to their real physical world. Many current innovations using augmented reality targeted at the elderly are designed to help those who are weak or who require constant monitoring and to enhance the physical ability of the elderly. A lots of research had been done in this area and the results were encouraging [4], [5], [6]. However, there are comparatively less studies on using augmented reality to stimulates the cognitive or psychomotor skills of the elderly such as paying attention, visual-motor coordination, logical spatial reasoning, visual perception, spatial orientation and creativity.

With technologies improvements and affordable price of mobile devices, the researchers on mobile gaming for elderly are mushrooming [7], [8]. Studies showed that mobile gaming can increase the cognitive abilities of elderly at the same time give the elderly sense of enjoyment and reduce the feeling of loneliness. The acceptance of elderly in the mobile gaming is seeing a rise but the elderly still prefer to engage to the thing that mimic the reality and relate to their life [9]. Hence, enhancing the mobile gaming with augmented reality may improve the gaming experience of the elderly. Augmented reality technologies have been used to enhance traditional games and the results are positive, but most of the focus are on the gaming for the younger age people. There is relatively little work on the augmented reality gaming application that targeted elderly. Augmented reality is certainly having an important potential for the game industry; however, it is still difficult to design augmented reality games that would appeal to the aging population. There is lack of studies on the acceptance of augmented reality in gaming and the effect of the augmented reality gaming on the elderly.

In this project, an Augmented Reality 3D cubes Puzzle Bingo game (ARPinGo) was developed by adapting the idea of rubik cubes and the puzzle and bingo board game features that the elderly are familiar with. Research from University of Deusto showed that puzzle game can enhance the psychomotor skill of the elderly [10], and study conducted by the Centre for Visual Cognition at Southampton University's Psychology Department revealed that the game of bingo can advance the speed and precision of short-term memory and actually helps in countering some aging effects [11]. Surveys were carried out to study the response of the elderly towards the game and their acceptance of augmented reality technologies in mobile gaming. The insights of the surveys shall provide valuable input for future development of a better gaming for the elderly. 


\section{TeChNiQues AND DEVElopMent ToOlS}

Currently there are two existing techniques in developing augmented reality system, marker-based technique which uses camera and visual cues to spawn virtual objects (markers), and marker-less technique [12]. In marker-based technique, the marker tracking pipeline is computationally inexpensive because it uses physical marker, so it does not use process exhausting recognition algorithm like the one used in markerless technique [13], although by using a marker, the marker must be placed in the sensing range. But according to João [14], in marker less augmented reality, any part of the real environment can be used as a marker that can be tracked in order to hold virtual objects. Therefore, there are no ambient disturbing markers that are not really part of the real world. However, the drawback is that the tracking and registration process are more complex in marker less augmented reality systems rather than in marker based.

In this project, marker-based technique is used with objective to develop a simpler augmented reality game that is easier to be adapted by the elderly people. There are lots of tools exist for augmented reality software development. Some are open source while some are commercial. Amongst the open source tools, two that are commonly used are Vuforia and ARToolkit. Vuforia is a broadly used Augmented Reality development tool. Its strength is the computer vision-based image recognition and tracking. It can perform well in low light condition or even when the marker is partially covered [15]. ARToolkit is an augmented reality developing tool mainly uses 2D square markers with variance of patterns, it does not support $3 \mathrm{D}$ object tracking [16]. ARToolkit has a fast image tracking rate for a real-time application. ARToolkit also provides multiplatform video library with multiple input sources and multiple cameras tracking [15]. In terms of tracking and image recognition Vuforia is better than ARToolkit. Although ARToolkit provides faster marker tracking rate, precision is more important than speed. Hence, Vuforia is used as the development tool for the project.

\section{ApPlicAtion ARCHITECTURE}

ARPinGo consists of three development sections, each section contributes different functionalities to the completed game. Vuforia handles the image targets (markers), it acts as the database for the markers and the augmented reality plugins for the unity3D. The Unity3D serves as the platform for assigning 3D objects to target images set in the Vuforia database and also used for implementing scripts to the 3D objects. Lastly the Android Studio is used to create the game's UI and logics.

\section{A. Vuforia}

The very first step of using Vuforia plugins for unity3D is to register a developer account. The account is compulsory in order to generate a license key for using created image targets databases. Only one license key is needed for the project to use multiple databases. After generating the license key, databases can be created. Databases are used to store all of the target images which are used as the markers. These images will then be rated by the Vuforia website in terms of augmentable features e.g. how easy it is to be recognized by augmented reality camera.
The databases can then be downloaded and used in unity3D after all of the required target images are added to the desired database(s).

\section{B. Unity3D}

The Unity3D is used to assign the objects to image targets. All of the image targets can be downloaded after initializing the database and its contents. Image targets are generated by dragging the Image target instances from the Vuforia > Prefabs folder, and choosing which database and image are going to be used for the image targets. As for the model, they were downloaded from the asset store. To use the model, search the model folder from the downloaded assets folder, then drag the $3 \mathrm{D}$ model to be used as object target into the desired image target.

LeanTouch library is used in Unity3D to receive the users touch inputs and recognizing them effectively. The library is an open source library which can be downloaded from the Unity asset store. For every object that has LeanSelectable script, each of them has three methods namely OnSelect (determine what will happen when the object is selected), OnSelectUp (determine what will happen when the selecting finger has finished touching), and OnDeselect (determine what will happen when the selected object is deselected. The audio file is put in the OnSelect script which will trigger the audio to play when an object is selected.

\section{Android Studio}

The platform of this application is on Android operating system. Android Studio is used in the project to create the user interfaces and the game logics along with the method called from the Unity's side. The Unity part of the project along with the Vuforia plugins are integrated into Android Studio project. In Unity, the project is converted into an Android Studio gradle (build system) and then be exported into the Android Studio project. The built project will consist of a class (activity) that manage the entire Unity project.

The user interfaces consist of splash screen, main menu, help instruction, camera screen, and the winning screen. Every screen other than the camera screen are designed using the $\mathrm{xml}$. The camera screen is programmatically modified to avoid it overlaps with the other elements on the screen. A subview instead of a view is used and it is put into a FrameLayout that only takes up two thirds of the screen. The rest of the screen is used to display the bingo board and the hints of the game.

\section{APPLICATION OVERVIEW}

ARPinGo is an augmented reality game that consists of both the virtual and physical components: a mobile application (virtual) and nine 3D puzzle cubes (physical). Fruits are used instead of numbers for the Bingo board because elders are more engaged with the objects that they can relate to their daily life, and visually rich contents are preferred over numbers.

ARPinGo is designed with simple interfaces to allow easy navigation and adaptation by the elderly. The first landing page when the game started is the Main Menu page. There are three menu: Start, Help and Exit, player can click the Help menu to 
display the game guidelines and click the Start menu to start playing the game. When the game started, a $3 \times 3$ bingo board consists of random fruit images is generated as shown in Fig 1. Four types of fruits are used in this application: apple, banana, kiwi and strawberry.

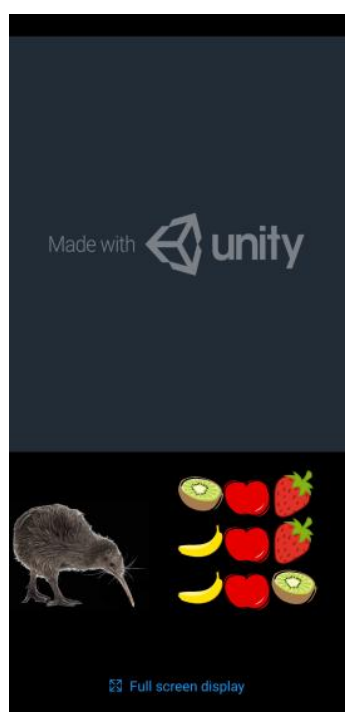

Fig. 1. Bingo Board Screen.

At the side of the Bingo board is the space where the hint will be displayed. The fruits are to be collected in sequence based on the hints given. The player need to collect all the fruits in the Bingo board in order to win the game. There are two types of hints: direct and indirect hints. The direct hints will tell the user the fruit to be collected by displaying the fruit images such as in Fig. 2 and Fig. 3. While the indirect hints will give some clues related to the fruit where the player need to make a guess as shown in Fig. 4 and Fig. 5.

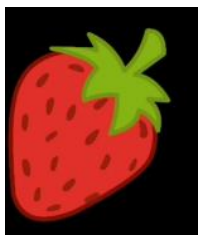

Fig. 2. Direct hint: strawberry.

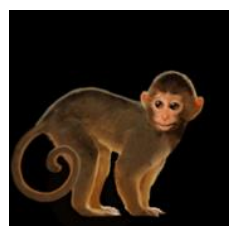

Fig. 4. Indirect hint: banana.

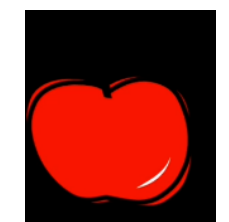

Fig. 3. Direct hint: apple.

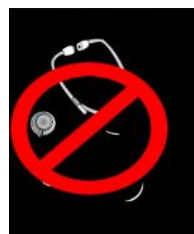

Fig. 5. Indirect hint: apple.
The indirect hint requires higher cognitive ability compared to direct hints. The mixture of hints with different difficulties level will make the game more interesting and to enhance the cognitive ability as well as engagement of the elders. Research discovered that the elderly are interested in higher cognitive load gaming design instead of the simple gaming features [9].
After the hint is resolved, the player has to solve the fruit puzzle before the fruit can be collected. Nine 3D cubes are provided as shown in Fig. 6.
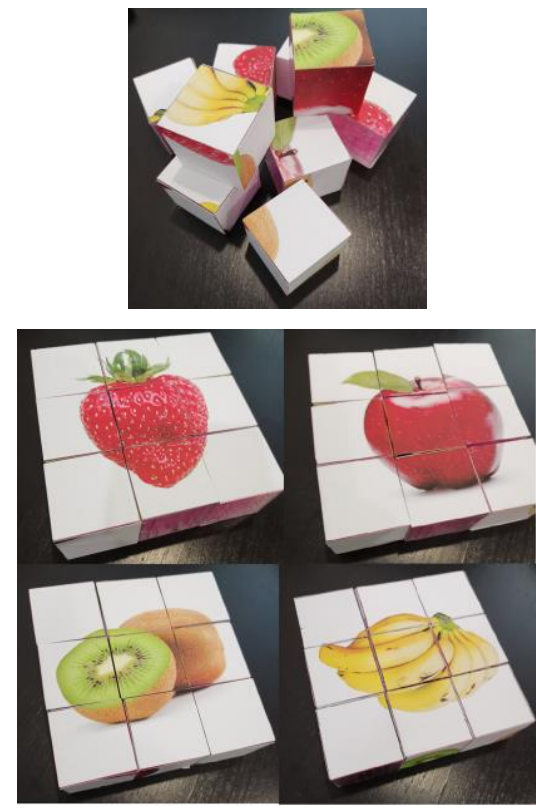

Fig. 6. 3D cubes.

Upon completing the puzzle, player is required to capture the fruit image with the application. Once the marker is recognised by the application, a 3D fruit model will pop up on the screen as shown in Fig 7. Player can rotate the screen to see the fruit from different angles.

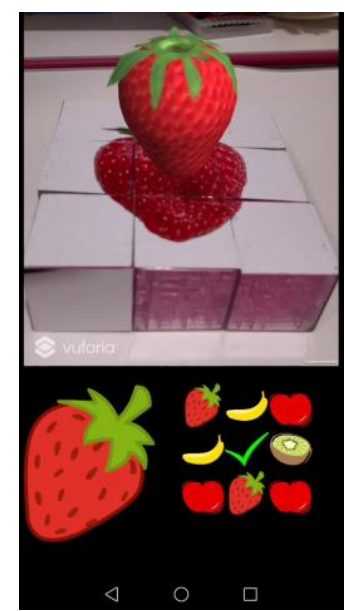

Fig. 7. Strawberry model in augmented reality.

The player shall then click on the model to collect the fruit and the respective fruit on the Bingo board is considered colleted and a tick will be displayed in the box. If the player touches the wrong fruit, a buzz sound will be prompted. The game will end once the player successfully collected all the fruits with 9 ticks, as shown in Fig. 8. 


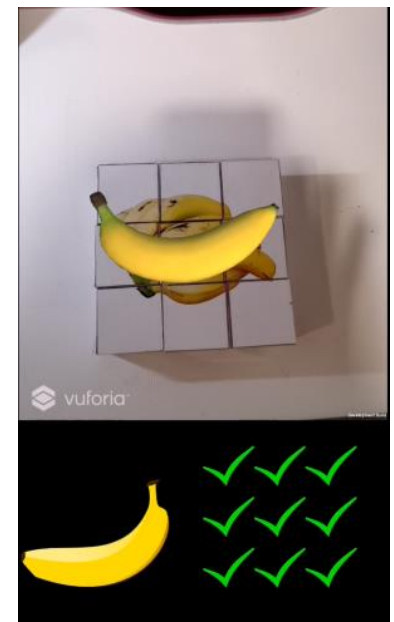

Fig. 8. Nine ticks on the Bingo board.

\section{Results DisCussion}

A study had been carried out with a group of elderly from D'Happy club in Petaling Jaya, Malaysia by first letting them play the game (Fig 9) and follow up with a survey.

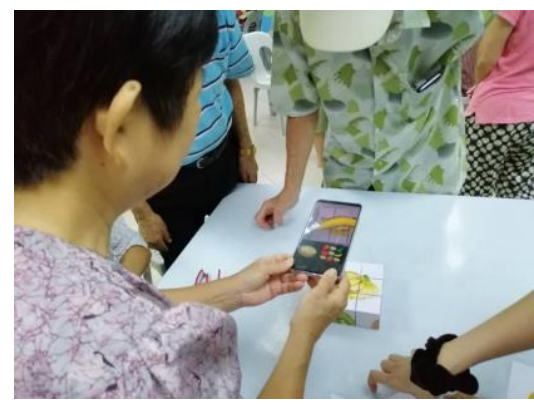

Fig. 9. Elderly from D’Happy club is playing the game.

This survey is run by voluntarily basis and has obtained a very good response where all the 24 elderly took part in the survey. The high response rate has indicated an initial interest of the elderly in the augmented reality technology. The participants' profiles are collected based on gender and age. $67 \%$ of the participants are female and $25 \%$ are male, and $8 \%$ do not specify the gender. Majority of the participants are above 60 years old, with $12 \%$ from age group of 50-60, $46 \%$ from age group of 61-70 and $42 \%$ from age group above 70 years old.

Survey questionnaire consists of 12 questions based on the Technology Acceptance Model (TAM) [17] to analyze the acceptance level of the elderly on playing the augmented reality game and 3 questions to analyze the cognitive load, relevance and attention (CAR) [18] of the elderly during the game, and the last open question to capture any additional comments from the participants. Individual factors such as age, gender and innovativeness are external variables in the study. Technology Acceptance Model (TAM) is the most frequently used theories utilized a quantitative approach to determine the user acceptance of any technology perceived usefulness and ease of use factors
[19], [20]. From the perspective of TAM, perceived ease of use, perceived usefulness, user satisfaction and attribute of usability are assumed to be related to the acceptance of a technology system [21]. In this project, the perceived usefulness is modified to the context of gaming study and assessed by means of enjoyment in playing the game, worded as perceived enjoyment.

The questions are as per listed in TABLE I. Question 1-3 evaluate the Perceived Innovativeness (PI), question 4-6 evaluate the Perceived Enjoyment (PE), question 7-9 evaluate the perceived Ease of use (PEOU), question 10-12 assess the Attitudes Toward Using (ATU) and question 13-15 assess the Behavioral Intention (BI). The last three questions 16-18 assess the cognitive load (C), attention (A) and relevance (R) of the game design.

\section{TABLE I. SURVEY QUESTIONS}

\begin{tabular}{|c|c|}
\hline & Perceived Innovativeness (PI) \\
\hline Q1 & $\begin{array}{l}\text { I am sure I will be one of the firsts who will try augmented } \\
\text { reality game. }\end{array}$ \\
\hline Q2 & I am keen to learn and explore new technologies. \\
\hline \multirow[t]{2}{*}{ Q3 } & I am interested in playing new mobile/computer game. \\
\hline & Perceived Enjoyment (PE) \\
\hline Q4 & Playing the game with augmented reality seems fun to me. \\
\hline Q5 & $\begin{array}{l}\text { Augmented reality makes gaming process more pleasant and } \\
\text { enjoyable. }\end{array}$ \\
\hline \multirow[t]{2}{*}{ Q6 } & $\begin{array}{l}\text { In my opinion, augmented reality may improve the gaming } \\
\text { experience. }\end{array}$ \\
\hline & Perceived Ease of Use (PEOU) \\
\hline Q7 & I think the game with augmented reality is easy to play. \\
\hline Q8 & $\begin{array}{l}\text { In my opinion, to learn how to play the game with augmented } \\
\text { reality is simple. }\end{array}$ \\
\hline \multirow[t]{2}{*}{ Q9 } & $\begin{array}{l}\text { I think that I can be skillful in playing the game with } \\
\text { augmented reality. }\end{array}$ \\
\hline & Attitudes Toward Using (ATU) \\
\hline Q10 & $\begin{array}{l}\text { I am positive about playing game with the feature of augmented } \\
\text { reality. }\end{array}$ \\
\hline Q11 & $\begin{array}{l}\text { The augmented reality features in the game attracts me to engage } \\
\text { more with the activities. }\end{array}$ \\
\hline \multirow[t]{2}{*}{ Q12 } & The use of the augmented reality in gaming is a good idea. \\
\hline & Behavioral Intention (BI) \\
\hline Q13 & $\begin{array}{l}\text { I think the augmented reality game can motivate me to play more } \\
\text { game in the future. }\end{array}$ \\
\hline Q14 & $\begin{array}{l}\text { I think I will recommend the augmented reality game to my } \\
\text { friends. }\end{array}$ \\
\hline \multirow[t]{2}{*}{ Q15 } & $\begin{array}{l}\text { If I were to play computer game in the future, I would choose to } \\
\text { play the game with augmented reality. }\end{array}$ \\
\hline & Cognitive (C) \\
\hline \multirow[t]{2}{*}{ Q16 } & $\begin{array}{l}\text { Please indicate the degree of difficulty level in completing [the } \\
\text { game]. }\end{array}$ \\
\hline & Attention (A) \\
\hline \multirow[t]{2}{*}{ Q17 } & [The game] has things that stimulated my interest and curiosity \\
\hline & Relevance (R) \\
\hline Q18 & $\begin{array}{l}\text { I could relate [the game] to things I have seen, done or thought } \\
\text { about in my life. }\end{array}$ \\
\hline
\end{tabular}


Seven-point Likert scale is used in the questions, with 1 as 'Strongly Disagree and 7 as 'Strongly Agree. A summary of the findings, the means, standard deviations and skewness are listed in TABLE II.

TABLE II. SURVEY RESULTS

\begin{tabular}{lccccccccc}
\hline & Q1 & Q2 & Q3 & Q4 & Q5 & Q6 & Q7 & Q8 & Q9 \\
\hline $\mathbf{N}$ & 24 & 24 & 24 & 24 & 24 & 24 & 24 & 24 & 24 \\
Mean & 4.3 & 5.8 & 4.9 & 5.3 & 5.3 & 5.7 & 5.2 & 4.9 & 4.6 \\
$\begin{array}{l}\text { Std. } \\
\text { Deviation }\end{array}$ & 1.4 & 0.9 & 1.4 & 1.2 & 1.2 & 1.1 & 1.2 & 1.3 & 1.3 \\
Skewness & 0.7 & -0.5 & -0.1 & -0.2 & 0.4 & -0.7 & -0.6 & 0.1 & -0.2 \\
\hline & $\mathbf{Q 1 0}$ & $\mathbf{Q 1 1}$ & $\mathbf{Q 1 2}$ & $\mathbf{Q 1 3}$ & $\mathbf{Q 1 4}$ & $\mathbf{Q 1 5}$ & $\mathbf{Q 1 6}$ & $\mathbf{Q 1 7}$ & $\mathbf{Q 1 8}$ \\
\hline $\mathbf{N}$ & 24 & 24 & 24 & 24 & 24 & 24 & 24 & 24 & 24 \\
Mean & 5.1 & 5.2 & 5.6 & 4.9 & 5.2 & 4.7 & 5 & 4.8 & 5.3 \\
Std. & & & & & & & & & \\
Deviation & 1.3 & 1.4 & 1.1 & 1.4 & 1.3 & 1.4 & 1.2 & 1.3 & 1.0 \\
Skewness & -0.3 & -0.4 & -0.1 & -0.2 & -0.4 & -0.2 & -0.4 & -0.7 & -0.5 \\
\hline
\end{tabular}

The overall responses are positive with the mean of score at 5.1. The results have further confirmed the initial observation that the participants are interested in the augmented reality game. Q2 has the highest mean of 5.8 indicated that generally the elderly were interested and keen to learn new technologies. The high mean of Q6 and Q12 shows that the elderly agreed that the use of augmented reality in gaming is a good idea and can improve the gaming experience.

The average scores grouping based on TAM are shown in Fig. 10 .

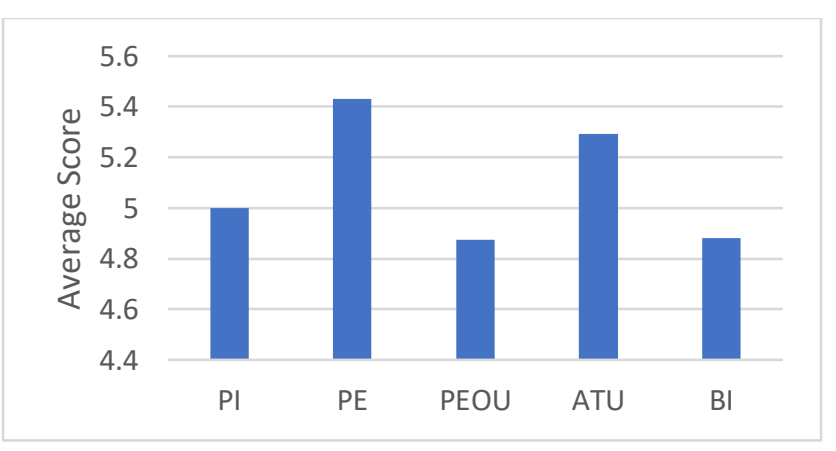

Fig. 10. Average score by TAM groupings.

The results show a stronger positive response on the Perceived Enjoyment (PE) and Attitudes Toward Using (ATU) grouping. This indicates that the elderly were attracted to play and enjoyed playing the augmented reality game. This finding suggests that when a person think that the game is fun to play, he/she will likely be positive in playing the game. On the other hand, the elderly felt that the augmented reality game although not difficult but is relatively not very easy to play, which can be observed from the slightly lower scores of Perceived Ease of Use (PEOU) grouping. They were also slightly reserved in playing more augmented reality game which is supported by the equally low readings in Behavioral Intention (BI) grouping. It is interesting to learn that the positivity attitude towards the game might not necessarily lead into the equally high motivation to play the game. This behavior likely be influenced by the personnel interest to explore new technology (PI) and the perception of difficulty in playing the augmented reality game (PEOU) where the elderly may afraid that they do not have enough skill to complete the game.

The average scores of questions related to cognitive, attention and relevance are shown in Fig. 11. The results show a stronger positive response on the relevance grouping. The elderly felt that the ARPinGo game is relevance to their daily life activities as they are familiar with the game objects (the fruits). The result of cognitive and attention grouping shows that the difficulty level of the ARPinGo game was well accepted by the elderlies. The implementation of the 3D cubes which requires physical involvement, and the mixture of direct and indirect hints manage to increase the cognitive load, while continue engaging the elderly in playing the game and having fun. It is not too difficult for them to complete the game at the same time it is not too simple to catch their attention and provide them curiosity to continue exploring the game and stay focus.

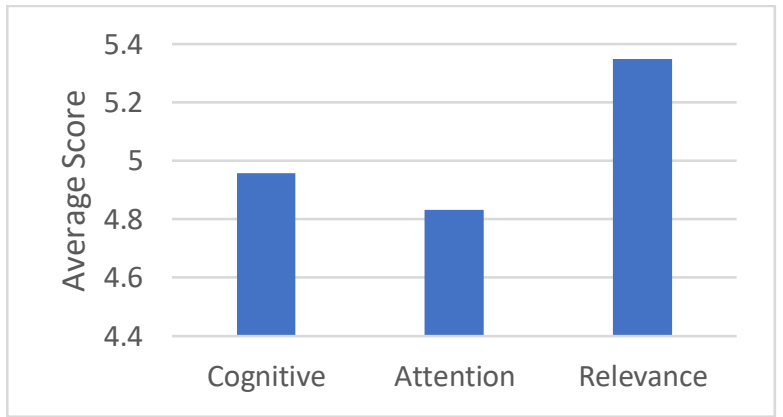

Fig. 11. Average score by CAR groupings.

TABLE III. CORRELATION ANALYSIS

\begin{tabular}{lcrlcccc}
\hline & PI & \multicolumn{1}{c}{ PE } & PEOU & ATU & BI & C & A \\
\hline PE & 0.4692 & 1.0000 & & & & & \\
PEOU & 0.4968 & 0.3366 & 1.0000 & & & & \\
ATU & 0.3764 & $\mathbf{0 . 7 7 0 4}$ & 0.5466 & 1.0000 & & & \\
BI & 0.5676 & 0.6460 & 0.4325 & $\mathbf{0 . 6 3 8 9}$ & 1.0000 & & \\
C & 0.3940 & -0.0460 & 0.4148 & 0.1611 & 0.3007 & 1.0000 & \\
A & 0.5691 & 0.3233 & 0.3889 & 0.4497 & $\mathbf{0 . 7 2 3 5}$ & 0.5915 & 1.0000 \\
R & 0.0000 & 0.6125 & 0.1383 & $\mathbf{0 . 6 7 3 4}$ & 0.5265 & 0.1100 & 0.3324 \\
\hline
\end{tabular}

When analyzing the multivariate linear regression analysis with Pearson correlation coefficient between the different TAM and CAR groupings (TABLE III), it is observed that a significant correlation between PE and ATU is found at $r=$ $.7704, \mathrm{p}<.0001$ and between ATU and BI at $r=.6389, \mathrm{p}<.001$. Besides that, strong correlations are also found between Attention and BI at $r=.7235, \mathrm{p}<.0001$ and between Relevance and ATU at $r=.6743, \mathrm{p}<.001$. On the other hand, there is no significant correlation between Cognitive and the TAM groupings, and weak correlation is found between PI and ATU. These findings support the hypothesis of 1) Elderly who think augmented reality game is fun have positive attitude towards playing the game with augmented reality features. 2) Elderly with positive attitude towards augmented reality game are likely 
to play more and recommend the game to their friends. 3) Elderly are motivated to play the augmented reality game which the contents are related to their daily life objects or activities. 4) Elderly are likely to play augmented reality game with features that able to trigger their interest and curiosity. 5) The level of difficulty in completing the game has less influence on the attitude of the elderly towards playing the augmented reality game. 6) The acceptance of augmented reality does not correlate with the interest in exploring new technology and playing mobile/computer game.

The last question in the survey is an open question to gather the suggestions and comments regarding the augmented reality game. Generally, the elderly responded with positive comments such as 'one feels you can occupy your time', 'keeps the mind alert and active', 'I think the possibilities are endless. Very interesting', 'could be interactive i.e. involving a few players to make it more fun/interesting'. When asked about any other area that augmented reality can benefit them besides gaming, some have given some suggestion such as 'teaching sign/traffic', 'calculating' and 'augmented reality should be a system that teaches a person in the reality of the situation'.

\section{CONCLUSION}

This project has successfully demonstrated the developing of an augmented reality game with both physical and virtual components comprises of the 3D cubes, puzzle and bingo features targeted the elderly users. The game which was developed using augmented reality techniques with a novel form of interaction through traditional activities (completing the puzzle cubes) has proved that it is possible to enrich the gaming experience enjoyed by the elderly. The findings show that the game was well accepted by the elderly, the level of difficulty is enough to capture their attention and the content is relevant and able to trigger their curiosity.

This research also reveals a good acceptance of augmented reality in gaming by the elderly. Majority of the participants had shown a high interest and positive attitude towards playing the augmented reality game. This research also shows that elderly were more engaged with the game that is fun and able to trigger their curiosity. The level of difficulty in completing the game has less influence on the attitude and acceptance of the elderly towards playing the augmented reality game. On the other hand, the result shows that the interest of elderly in playing mobile/computer game and exploring new technology does not directly influence their acceptance of augmented reality in gaming.

By providing tangible evidence on the acceptance of augmented reality gaming by the elderly, this finding could help more people develop better gaming application and augmented reality system for the elderly in terms of social engagement, daily tasks and assistive training.

\section{ACKNOWLEDGMENT}

Thanks to Sunway University, Prof. Dr. Lee Chien Sing for contribution in the ideas and discussions [22].

\section{REFERENCES}

[1] ONU, "Report on world population ageing," p. 164, 2015.

[2] J. Younbo, "Promoting Active Ageing through Virtual \& Augmented Reality," 2019.

[3] S. Coughlan, "Loneliness: The cost of the "last taboo," BBC News education and family correspondent, 2017.

[4] J. R. Bruun-Pedersen, K. S. Pedersen, S. Serafin, and L. B. Kofoed, "Augmented exercise biking with virtual environments for elderly users: A preliminary study for retirement home physical therapy," 20142 nd Work. Virtual Augment. Assist. Technol. VAAT 2014; Co-located with 2014 Virtual Real. Conf. - Proc., pp. 23-27, 2014.

[5] S. Okuno, T. Ito, M. Suzuki, and S. Tani, "Gait diagnosis for elderly people to prevent fall and development of training assist tool using augmented reality," MHS 2017 - 28th 2017 Int. Symp. MicroNanoMechatronics Hum. Sci., vol. 2018-Janua, pp. 1-6, 2018.

[6] J. R. Bruun-Pedersen, S. Serafin, and L. B. Kofoed, "Motivating elderly to exercise - Recreational virtual environment for indoor biking," 2016 IEEE Int. Conf. Serious Games Appl. Heal. SeGAH 2016, pp. 1-9, 2016.

[7] O. Mubin, S. Shahid, and A. Al Mahmud, "Walk 2 Win: Towards Designing a Mobile Game for Elderly's Social Engagement," ... , Creat. Interact. 2, pp. 11-14, 2008.

[8] W. Y. Foo, W. N. Lim, and C. S. Lee, "Drawing guessing game for the elderly," in IEEE Region 10 Annual International Conference, Proceedings/TENCON, 2017, vol. 2017-Dec, pp. 2236-2241.

[9] Y. J. Chin, W. N. Lim, and C. S. Lee, "Mobile Game for the Elderly Bundled Bingo Game," in IEEE Region 10 Annual International Conference, Proceedings/TENCON, 2017, vol. 2017-Dec, pp. 2262-2267

[10] B. García Zapirain, A. Méndez Zorrilla, and S. Larrañaga, "Psychostimulation for elderly people using puzzle game," 2 nd Int. IEEE Consum. Electron. Soc. Games Innov. Conf. ICE-GIC 2010, 2010

[11] D. Regan, "Recent Research Reveals Elderly Play Bingo for Cognitive Benefits." [Online]. Available: http://www.best-onlinebingo.com/research-elderly-play-for-cognitive-benefits-020807.html.

[12] A. Katiyar, K. Kalra, and C. Garg, "Marker Based Augmented Reality Browser," IRACST -International J. Comput. Sci. Inf. Technol. Secur., vol. 2, pp. 441-445, 2015

[13] S. Cukovic, M. Gattullo, F. Pankratz, G. Devedzic, E. Carrabba, and K Baizid, "Marker Based vs. Natural Feature Tracking Augmented Reality Visualization of the 3D Foot Phantom," Int. Conf. Bio-medical Eng., no. June, pp. 24-31, 2015

[14] J. P. Lima, F. Simões, L. Figueiredo, and J. Kelner, "Model Based Markerless 3D Tracking applied to Augmented Reality," $S B C J .3 D$ Interact. Syst., vol. 1, pp. 2-15, 2010.

[15] D. Amin and S. Govilkar, "Comparative Study of Augmented Reality Sdk's,” Int. J. Comput. Sci. Appl., vol. 5, no. 1, pp. 11-26, Mar. 2015

[16] "AR frameworks Comparison." [Online]. Available: http://socialcompare.com/en/comparison/ar-frameworks-388frkga.

[17] F. D. Davis, "Perceived Usefulness, Perceived Ease of Use, and User Acceptance of Information Technology," MIS Q., vol. 13, no. 3, p. 319 , 1989

[18] S. F. Wong, "ARCS questionnaire.” Questionnaire, Sch. of Science and Technology, Sunway University, 2016.

[19] R. Pascoal, B. Alturas, A. De Almeida, and R. Sofia, "A survey of augmented reality: Making technology acceptable in outdoor environments," Iber. Conf. Inf. Syst. Technol. Cist., vol. 2018-June, no. 351, pp. 1-6, 2018.

[20] E. Erasmus, S. Rothmann, and C. Van Eeden, "A structural model of technology acceptance," SA J. Ind. Psychol., vol. 41, no. 1, pp. 1-12, 2015 .

[21] H. M. Abu-Dalbouh, "A questionnaire approach based on the technology acceptance model for mobile tracking on patient progress applications," J. Comput. Sci., vol. 9, no. 6, pp. 763-770, 2013

[22] M. May Yin and L. Chien Sing, "Augmented Reality (AR) Puzzle Matching Game,” B.S. Thesis, Sch. of Science and Technology, Sunway University, 2019 